\title{
Narrativa esportiva de MOBA: que gênero é esse?
}

\author{
Danilo Sobral de Souza \\ Márcia Helena de Melo Pereira \\ Adilson Ventura
}

Universidade Estadual do Sudoeste da Bahia - UESB - Vitória da Conquista - Bahia - Brasil

\begin{abstract}
Resumo: O presente artigo apresenta resultados de uma investigação sobre a narrativa esportiva de $M O B A$, considerada aqui enquanto um novo gênero discursivo. Nosso objetivo é investigar esse gênero tendo em vista seus aspectos temáticos, composicionais e estilísticos. Para tanto, lançamos mão dos conceitos bakhtinianos sobre dialogismo e gênero discursivo. O corpus foi composto de dois excertos de narrativas esportivas de League of Legends, realizadas no Brasil: uma em um campeonato e outra em um programa de televisão. Para a construção da análise, estabelecemos paralelos com a narração de futebol, a fim de entender as especificidades da narrativa esportiva de MOBA. Como conclusão, apontamos que as características principais da narrativa de MOBA, enquanto elementos que particularizam essa instância comunicativa, são o aspecto multifocal do olhar do narrador e o controle do espectador.
\end{abstract}

Palavras-chave: Gênero textual, MOBA, narrativa esportiva, narrador.

Abstract: This article presents results from the investigation of the sports narrative of MOBA considered as a new discursive genre. In order to do so, we use Bakhtin's concepts of dialogism and his understanding of the configuration of the genres of discourse, essential for the understanding of this subject. The corpus was composed of two excerpts from League of Legends sports narratives, made in Brazil: one in a league and the other in a television program. For the construction of the analysis, we established certain parallels with the soccer narration in order to understand the specificities of the MOBA sportive narrative. As a conclusion, we point out that the main characteristics of the MOBA narrative are the multifocal aspect of the narrator's gaze and the control of the spectator as elements that particularize this communicative instance.

Keywords: Textual genre, MOBA, sports narrative, narrator. 


\section{Introdução}

Os gêneros discursivos contribuem para a estabilização das atividades comunicativas, são fluidos e não estanques. Criados a todo instante, novos gêneros surgem de acordo com as necessidades socioculturais, com 0 intuito de aumentar 0 "[...] poder interpretativo das ações humanas em qualquer situação [...] (MARCUSCHI, 2010. p.19) de comunicação. A narração esportiva de MOBA é um desses gêneros criados mais recentemente. Já prevista por estudos de Bakhtin (2003), a criação de novos gêneros não são inovações absolutas, conforme aponta Marcuschi (2010), pois eles se ancoram em modelos existentes, se configurando enquanto uma nova entidade sociodiscursiva.

Os e-sports, ou esportes eletrônicos, também são práticas recentes. Essa é a nomenclatura dada para as competições organizadas de jogos eletrônicos, especialmente entre os profissionais desse setor. Os gêneros de jogos mais comuns, associados com esportes eletrônicos, são os de RTS (Real Time Strategy), TCG (Trading Card Games), FPS (First Person Shooter), e MOBA (Multiplayer Online Battle Arena). Esses eventos fornecem tanto transmissões ao vivo de competições, como prêmios em dinheiro para os concorrentes. As competições têm atingido um grande aumento de popularidade nos últimos anos com a proliferação de campeonatos profissionais e a crescente audiência, o que resulta no advento de um número significativo de jogadores profissionais e equipes, revelando um mercado global multimilionário e um cenário bastante atrativo para novos praticantes e investidores. O website alemão The Esports Observer (https://esportsobserver.com/) compilou os 10 maiores e-sports em premiação no ano de 2018 , conforme quadro a seguir:
Quadro 1: Ranking de e-sports a partir de premiações entregues em competições em 2018.

\begin{tabular}{|l|c|c|}
\hline \multicolumn{1}{|c|}{ Nome do Jogo } & $\begin{array}{c}\text { Gênero } \\
\text { do jogo }\end{array}$ & $\begin{array}{c}\text { Valor total } \\
\text { pago em } \\
\text { dólares }\end{array}$ \\
\hline Dota 2 & MOBA & $\$ 41.260 .000$ \\
\hline $\begin{array}{l}\text { Counter-Strike: } \\
\text { Global Offensive }\end{array}$ & FPS & $\$ 22.470 .000$ \\
\hline Fortnite & FPS & $\$ 19.960 .000$ \\
\hline League of Legends & MOBA & $\$ 14.120 .000$ \\
\hline $\begin{array}{l}\text { PlayerUnknown's } \\
\text { Battlegrounds }\end{array}$ & FPS & $\$ 6.730 .000$ \\
\hline Overwatch & FPS & $\$ 6.700 .000$ \\
\hline Heroes of the Storm & MOBA & $\$ 6.520 .000$ \\
\hline Hearthstone & TCG & $\$ 4.950 .000$ \\
\hline StarCraft II & RTS & $\$ 4.530 .000$ \\
\hline Call of Duty: WWII & FPS & $\$ 4.170 .000$ \\
\hline
\end{tabular}

Fonte: Adaptado de https://esportsobserver.com/10biggest-prize-pools-2018/ Acesso em 24/02/2019.

Neste artigo, pretendemos investigar a narração esportiva de $M O B A$ e tentar caracterizar esse gênero, ou seja, entendê-lo a partir dos três pilares que compõem os gêneros, conforme postulou Bakhtin (2003): conteúdo temático, estilo e estrutura composicional. Escolhemos a narrativa esportiva de $M O B A$ por este gênero liderar o ranking mundial de premiações. Compomos nosso corpus com a transcrição de dois excertos de duas narrativas de League of Legends (LOL). O motivo pelo qual se adotou esse jogo é o fato de, no território brasileiro, o $L O L$ ser muito mais lucrativo do que o Dota2 e ter um cenário nacional de competições mais ativo, a exemplo do Campeonato Brasileiro de LOL (CBLOL), evento que ocorre anualmente desde 2012. Vale ressaltar que $L O L$ foi inspirado no jogo Dota, antecessor de Dota 2.

Para tanto, além dos estudos de Bakhtin (2003) a respeito dos gêneros do discurso, lançamos mão dos estudos de Fiorin (2006) e Marcuschi (2008, 2010) para fundamentar nossa investigação. Analisaremos dois excertos de duas narrativas de League of Legends: uma narrativa feita em um torneio 
(CBLOL) e outra apresentada em um programa de televisão.

Sendo assim interessa-nos, sobretudo, responder a seguinte questão: como é o gênero narrativa esportiva de MOBA? Discutiremos, a seguir, o conceito de gêneros do discurso a partir da ótica de Bakhtin, além de apresentar breves notas a respeito do MOBA e de narração.

\section{Os gêneros do discurso: o olhar de Bakhtin}

De acordo com Bakhtin (2003), os homens, em todas as suas atividades, fazem uso da linguagem em determinadas esferas sociais as quais estão vinculados, sejam elas referentes à escola, ao trabalho, à política, às relações interpessoais ou em quaisquer outras, e, a partir do interesse, intencionalidade e finalidade específicos de cada atividade, realizará enunciados linguísticos de maneiras diversas. Esses enunciados, para o filosofo, são dialógicos. O dialogismo é o modus operandi real da linguagem (Bakthin/Voloshínov, 2014). Em outras palavras, podemos entender que todo enunciado constitui-se a partir de outro enunciado, e, portanto, há nele pelo menos duas vozes, quais sejam: a de quem fala e a de para quem se fala. Além disso, Bakhtin/Voloshínov também alertam que, além dessa condição constituidora do enunciado, o dialogismo também pode ocorrer, enquanto incorporação por parte do enunciador, pela(s) voz(es) de outro(s) discurso(s). Podemos entender, então, que dialogismo é o modo de funcionamento real da linguagem e o modo de constituição do enunciado. É a partir desta ideia que Bakhtin (2003) pensa os gêneros do discurso. Para o filósofo, a língua se dá através do emprego de enunciados relativamente estáveis, concretos e únicos. Esses enunciados refletem a condição e o propósito do ato de comunicação e configuram-se em gêneros do discurso.

Com o objetivo de contribuir para a definição de gênero, Marcuschi explana que eles são "[...] fenômenos históricos, profundamente vinculados à vida cultural e social. Fruto do trabalho coletivo, [...] contribuem para ordenar e estabilizar as atividades comunicativas [...]" (MARCUSCHI, 2010. p.19). Em suma, é papel dos gêneros constituir uma interconectividade entre a linguagem e a vida social.

De acordo Bakhtin (2003), os gêneros são constituídos por três aspectos: conteúdo temático, estilo e organização composicional. O primeiro não pode ser confundido com o assunto específico de um texto, pois se deve entender como conteúdo temático o domínio semântico de que se vale o gênero. $O$ segundo diz respeito à seleção de determinados meios gramaticais, lexicais ou sintáticos em função da compreensão do enunciado. O ato estilístico é, pois, uma seleção de meios linguísticos. O terceiro é o modo de organização textual; sua estrutura.

O estudioso russo (2003), além disso, divide os enunciados em dois: os primários ou simples, que são predominantemente, mas não exclusivamente, orais, pertencem à vida cotidiana e surgem a partir de situações de comunicação discursiva direta, como, por exemplo, o bate papo, a conversa telefônica, o email; já os secundários ou complexos competem às esferas da comunicação cultural mais elaborada, como a política, a jurídica ou o jornalismo. Podem e muitas vezes são compostos por gêneros primários, que são absorvidos e transformados em situações discursivas complexas. Logo, entende-se que gêneros discursivos são maleáveis e fluidos.

Não obstante, assim como a humanidade está em constante movimento, as esferas de atividades humanas se tornam mais complexas e transformam seus respectivos gêneros, atribuindo-lhe um novo sentido, uma nova função. Gêneros desaparecem e tantos outros ascendem. Podemos pensar, por exemplo, no acréscimo de gêneros advindos da internet. $\mathrm{O}$ e-mail, que tem sua organização parecida ora com o gênero carta, ora com o recado; ou o tweet, que tem sua estrutura delimitada a um número máximo de caracteres. Nas palavras de Fiorin (2006):

Os gêneros são meios de apreender a realidade. Novos modos de ver e de conceptualizar a realidade implicam 0 aparecimento de novos gêneros e a alteração dos já existentes. Ao mesmo tempo, novos gêneros ocasionam novas maneiras de ver a realidade [...] Mesmo que alguém domine bem uma língua, sentirá dificuldade de participar 
de determinada esfera de comunicação se não tiver controle do(s) gênero(s) que ela requer [...] (FIORIN, 2006. p. 69).

Ou seja, é na percepção da relação entre as formas e as atividades que o gênero ganha sentido. $O$ gênero não pode ser entendido como uma forma fixa e/ou isolada de determinada esfera da ação humana. Instabilidade e estabilidade são suas características fundamentais.

Todavia, não se pode confundir gênero discursivo com tipo textual. A noção de tipo textual, segundo Marcuschi (2010), remete às diversas sequências linguísticas que podem ser encontradas em um único gênero e podem ser classificadas como: narrativa, descritiva, argumentativa, expositiva e injuntiva. Portanto, em um gênero pode-se encontrar tipos textuais diversos, o que faz com que o gênero discursivo seja tipologicamente variável. Contudo, não podemos pensar que gênero e tipo são dois elementos dicotômicos; é preciso pensar na relação complementar que é estabelecida entre um e outro. Em suma, o gênero discursivo, que pode conter vários tipos textuais, está inserido em um domínio discursivo, logo representa e/ou materializa o texto de um determinado domínio.

Outro aspecto importante para o entendimento do conceito de gênero é a questão do suporte. O suporte "[...] é um locus físico ou virtual com formato específico que serve de base ou ambiente de fixação do gênero materializado como texto [...]" (MARCUSCHI, 2008. p. 174). O suporte, seja como transporte ou meio de fixação, interfere diretamente no gênero, porém, o suporte não é exclusivamente determinador de gênero. É o gênero que "seleciona" um suporte especial, específico para a sua necessidade e realização. Contudo, há casos em que a mudança de suporte transforma o gênero como, por exemplo, se o texto "João, me liga urgente" for veiculado por um pedaço de papel, é um bilhete; se for gravado em uma secretária eletrônica, é um recado; se for enviado via celular, é um SMS; se for enviado pelo Twitter, é um tweet, e assim por diante, conforme nos lembrou Marcuschi (2010). Nesse caso, o gênero é identificado através de seu suporte, logo o conteúdo não muda. Nas palavras de Marcuschi
(2008): "[...] a) suporte é um lugar físico ou virtual; b) suporte tem um formato específico; c) suporte serve para fixar e mostrar o texto" (MARCUSCHI, 2008. p. 175).

Portanto, a partir desses apontamentos, podemos pensar no seguinte esquema ilustrativo a respeito do nosso objeto, a narrativa de MOBA, adaptado do esquema ilustrativo sobre a relação domínio discursivo/gênero textual/tipos textuais de Pereira \& Silva (2014, p. 186):

Figura 1: llustração sobre a relação domínio discursivo / gênero textual, tipos textuais / suporte

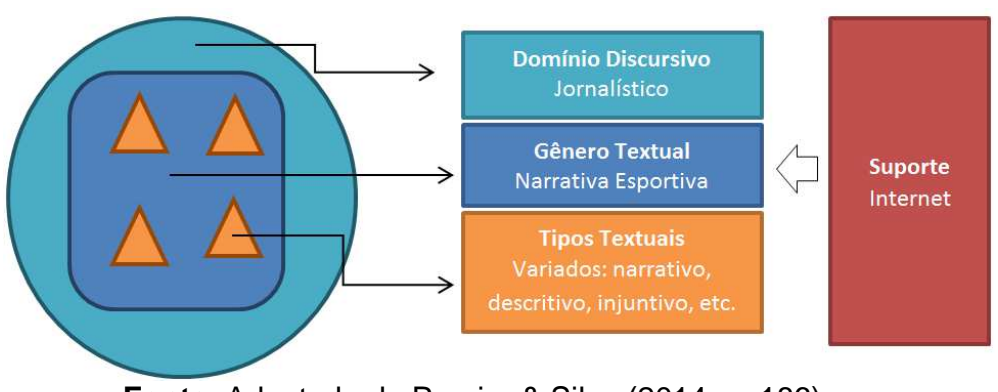

Fonte: Adaptado de Pereira \& Silva (2014, p. 186)

Porém, o que vem a ser MOBA? Como funciona a dinâmica do jogo? O que são os e-sports? Discutiremos essas questões a seguir.

\section{E-Sports e MOBA: noções sobre o jogo}

A obra Homo Ludens - o jogo como elemento da cultura, de Johan Huizinga, foi escrita em 1938. O livro, dividido em doze capítulos, propõe a discussão acerca do conceito de jogo e depois investe, entre outras questões, na relação entre jogo e guerra, direito, poesia, além de suas funções. Assim Huizinga conceitua jogo:

[...] O jogo é uma atividade ou ocupação voluntária, exercida dentro de certos e determinados limites de tempo e de espaço, segundo regras livremente consentidas, mas absolutamente obrigatórias, dotado de um fim em si mesmo, acompanhado de um sentimento de tensão e de alegria e de uma consciência de ser diferente da "vida quotidiana" [...] (HUIZINGA. p. 33)

Interessante é perceber como a construção do espaço ao qual o jogo se vincula já carrega a ideia da limitação do tempo e do espaço, como observa o 
autor, no excerto acima. O lugar do jogo (a arena, o campo, o palco, o templo etc.) é fechado e sagrado, tem suas regras encerradas em si e por si mesmas e é, sobretudo nesse sentido, que podemos perceber melhor a ideia da suspensão da vida corriqueira, pois tudo neste momento de suspensão vale segundo as regras que lhes são próprias.

É possível, após a leitura de Homo Ludens, traçar a importância central que tem o jogo para o homem até os nossos dias, quando passou a haver, por exemplo, uma sistematização cada vez maior do esporte, o que fez com que o jogo perdesse parte das suas características lúdicas, tornando-se, assim, profissional. Para o autor, "a existência do jogo é inegável. É possível negar, se se quiser, quase todas as abstrações: a justiça, a beleza, o bem, Deus. É possível negar-se a seriedade, mas não o jogo." (HUIZINGA, 1980, p. 6.)

O Multiplayer Online Battle Arena, abreviado como MOBA, que também pode receber a nomenclatura de Action Real-Time-Strategy (Action $R T S)$, é uma ramificação de jogos de computador. $\mathrm{O}$ MOBA (assumiremos essa nomenclatura por ser a mais divulgada) é um jogo de estratégia online no qual, geralmente, se enfrentam duas equipes de cinco membros. Ao contrário de outros jogos de estratégia em tempo real, como o xadrez, por exemplo, que se desenvolve através de turnos para cada jogador, 0 $M O B A$ se desenrola em tempo "real" - as equipes criam suas estratégias ao mesmo tempo.

$\mathrm{O}$ jogo pode acontecer online (vinculado aos servidores do jogo, em uma rede mundial) ou LAN (em uma rede local de computadores, sem a necessidade da interação de jogadores online), em uma modalidade $5 \times 5$ (duas equipes de cinco jogadores se enfrentando, com o objetivo de derrubar as torres inimigas), em uma modalidade $1 \times 1$ (apenas dois jogadores se enfrentam em uma modalidade específica), ou, ainda, em outros modos de jogos específicos de cada jogo, como player versus bots (modo em que o jogador enfrenta a inteligência artificial do computador).

A geografia do $M O B A$, ponto fundamental para o planejamento da estratégia, é bastante simples.
São três trilhas (Top, Middle, Bottom) que têm três torres de cada equipe. Estas trilhas, em seus extremos, dão acesso à base das respectivas equipes (Team base). O objetivo do jogo é atingido ao quebrarem-se as torres e a base da equipe inimiga. Entre as trilhas, há a selva (Team jungle) que oferece alguns atalhos que ligam determinados pontos das trilhas, além de haver acampamentos com criaturas neutras. A imagem a seguir, que pode ser chamada de mapa, elucida a geografia do jogo. Durante o jogo, ícones ${ }^{1}$ que demarcam cada jogador são vistos pelo mapa, item que compõe a tela de cada jogador. A figura a seguir representa a geografia de um mapa prototípico de $M O B A$ : as três trilhas (em amarelo), as torres e a Team Base de cada time (em azul e vermelho) e as team jungles (em verde).

Figura 2: Representação esquemática de um mapa de MOBA

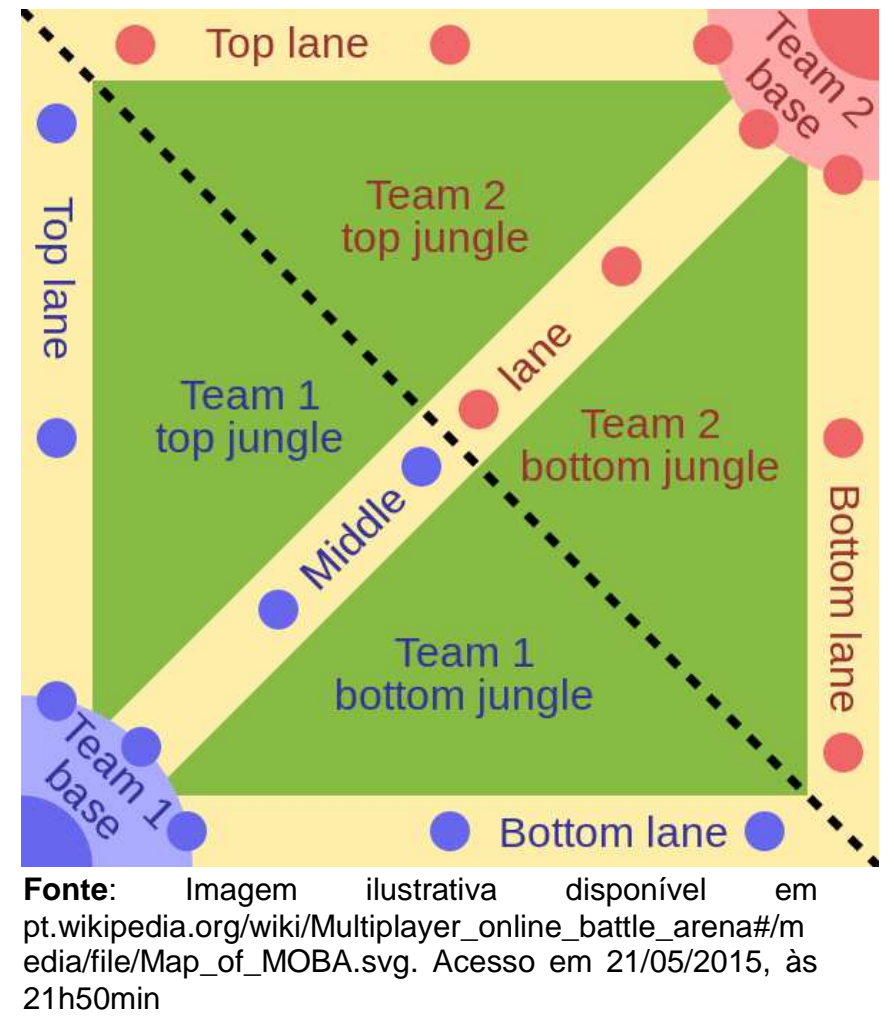

Todavia, este mapa não é totalmente iluminado; existem partes obscuras no mapa (fog)

\footnotetext{
${ }^{1}$ Os ícones podem se diferenciar por cores ou por desenhos representativos de cada personagem.
} 
que possibilitam a condição de emboscada ${ }^{2}$ (trap). Apenas parte das trilhas (uma área ao redor de cada torre) pertencentes ao time de um determinado jogador é naturalmente iluminado, ou seja, o lado do mapa do time adversário e a selva, em ambos os lados, são totalmente obscuros. Isso faz com que cada time se preocupe com a iluminação do mapa, forçando-os a instalar itens sentinelas, que garantem a visão do mapa, em locais estratégicos, impossibilitando qualquer tentativa de trap.

Periodicamente, durante o jogo, cada team base invoca uma leva de criaturas ${ }^{3}$ que marcham em direção às torres inimigas. Essa leva de criaturas é conjurada ao mesmo tempo pelas duas bases e caminham em quantidades iguais nas três trilhas. Essas criaturas se enfrentam e se matam, gerando, com sua morte, dinheiro para a equipe inimiga. No Dota2, por exemplo, se uma equipe conseguir derrubar as estruturas de uma das trilhas inimigas, essas criaturas se tornam supercreeps. Ao derrubar todas as torres e as estruturas de todas as linhas, as criaturas se tornam megacreeps. Tanto os super como os mega têm seus pontos de vida e dano muito superiores aos creeps normais. Isso faz com que o avanço sobre as trilhas inimigas se torne muito mais forte, facilitando a conquista do objetivo: a destruição da team base inimiga.

Em um MOBA, há uma quantidade limitada de personagens jogáveis. Cada personagem tem habilidades e funções específicas e apresentam vantagens contra uns e desvantagem contra outros personagens. Todos os jogadores iniciam com seus personagens no level 1 e, na maioria das vezes, começam com a mesma quantidade de dinheiro. No decorrer da partida, para atingir o objetivo global, cada equipe precisa matar o maior número de criaturas, adquirir determinada quantidade de dinheiro para comprar itens para seus personagens, além de evoluí-los e torná-los mais fortes. Ganha o jogo quem primeiro conseguir derrubar as torres de pelo menos

\footnotetext{
${ }^{2}$ Por exemplo, o jogador está na bottomlane do Team 1, e, por conta da fog, não percebe a chegada de outros jogadores pela Team 1 bottomjungle.

${ }^{3}$ Creep no Dota2 e minion no LeagueofLegends.
}

uma trilha, as torres da base, além de destruir a base inimiga. No $L O L$, há também a possibilidade de uma equipe solicitar o GG. O GG, sigla para good game, anuncia o fim do jogo. Uma equipe que escreve GG se rende, entrega a vitória à sua adversária.

Atualmente, League of Legends (LoL) e Dota2 são os grandes representantes dessa modalidade em competições de e-sports e carregam números bastante significativos em suas bagagens. $O$ primeiro é considerado o jogo online mais jogado do mundo, com aproximadamente setenta milhões de jogadores cadastrados, que jogam aproximadamente um bilhão de horas por mês. Em um dia comum, em toda a rede online de LoL, é normal registrar um pico de 3 milhões de pessoas online. $O$ segundo, que também registra picos de mais de um milhão de jogadores conectados em um dia comum, marcou a história de competições de jogos eletrônicos com o The International (torneio mundial de Dota2, que, em sua primeira edição, em 2011, premiou a equipe campeã um milhão de dólares americanos e distribuiu mais seiscentos e cinquenta mil dólares para outras sete equipes participantes). Uma comparação interessante: a $E G$, equipe americana que venceu o The International 5, recebeu uma premiação equivalente à $R \$ 23$ milhões, valor maior do que o que recebeu o último campeão da Copa Libertadores da América ${ }^{4}$ (a principal competição de futebol entre clubes profissionais da América do Sul, organizada pela Confederação Sul-Americana de Futebol CONMEBOL).

E, como em toda competição desportiva, não poderia faltar um elemento fundamental: o narrador. O narrador é o sujeito que descreve, à sua maneira, o que acontece em um certame. Normalmente, este locutor é jornalista e é acompanhado, em suas transmissões ao vivo, de um comentarista. comentarista esportivo é o jornalista que faz a análise de um esporte. A função de comentarista é comum nas transmissões esportivas ao vivo, e é comumente exercida por jogadores ou árbitros aposentados ou 4
her libertadores.html. acesso em 17/09/2015 às 07:11 
não. O comentarista não se presta a descrever os fatos ocorridos num evento esportivo, tarefa que cabe ao narrador. Por ser a peça central no gênero narração esportiva, propomos investigar o papel do narrador no gênero discursivo em análise.

\section{O narrador desportivo: engenheiro do gênero discursivo que narra}

A narração esportiva de $M O B A$ ou de qualquer outra modalidade desportiva é defendida aqui como gênero textual. Entendemos, também, que o narrador desportivo é o construtor do gênero discursivo, logo que narra àquilo que vê. Todavia, perguntamo-nos: toda narração desportiva tem configurações parecidas? Além disso, tudo o que é narrado é tudo o que ocorre durante o jogo em questão? Na tentativa de responder a estas duas questões, analisaremos comparativamente excertos de narração de $M O B A$ com excertos de narração de futebol.

Como não há nenhum trabalho científico que procura investigar a narrativa esportiva de MOBA, tarefa que estamos nos propondo a fazer, neste artigo, partiremos de estudos de gênero já publicados a respeito de narrativas de alguns jogos, como o futebol. Sobre essa temática, encontramos a dissertação de mestrado de Santos (2010), que trata da narração esportiva do futebol. Para construir a nossa comparação, discutiremos a respeito do papel do narrador de futebol e a respeito do papel do narrador de MOBA. Sobre o narrador de futebol, Santos (2010) explana que

[...] a principal função do narrador em uma
narrativa esportiva de futebol é relatar os
fatos, descrevê-los, ainda que narrados de
forma alinear, devido à especificidade do
evento narrado, pois uma partida de futebol se
desenrola com diversas jogadas coletivas ou
individuais, ações que se intercalam e que
compõem um todo articulado com sentido.
(SANTOS, 2010. p. 43 )

Em conformidade com Santos (2010), pensamos que o olhar do narrador da narrativa esportiva de futebol tem como foco a bola, uma vez que é ela a protagonista do jogo. Sem a bola não há futebol e tudo, durante o jogo, corre em torno dela. Os olhos do narrador não podem sair da bola, tanto que, se por acaso ocorrer qualquer outro lance digno de narração (e essa escolha é tão somente feita pelo narrador, que constrói o seu dizer), o narrador lança mão de mecanismos de repetição de imagens, como replays ou alertas dos repórteres de campo ou, ainda, de olhares dos comentaristas que participam da narração. Além disso, o narrador pode ser "traído" pela transmissão das imagens: se um narrador brasileiro está narrando uma competição veiculada por outra emissora que não seja a sua (como em campeonatos internacionais que podem ter contratos de transmissão exclusiva), e, em determinado momento ocorre uma briga na arquibancada ou uma briga de jogadores fora do lance da bola, o narrador pode ou não transmitir essa informação, pois fica à mercê do editor de imagens.

Este é um dos pontos em que podemos diferenciar a narração futebolística da narração de $M O B A$. A segunda é construída pelo narrador que escolhe o que narrar, assim como qualquer outro narrador, porém, diferentemente do futebol, no qual o foco é a bola, partidas de MOBA são "multifocais", pois o olhar do narrador pode estar presente em vários elementos durante o jogo. Jogadas podem ocorrer simultaneamente, forçando o narrador a escolher o que olhar/narrar. Todavia, o narrador tem controle da "câmera", podendo posicionar os olhos em qualquer canto do mapa que lhe for favorável.

Outro aspecto em que podemos pensar é o ato de narrar, que é construído dialogicamente com o público, logo que o narrador tenta construir uma ponte entre o (tele) espectador e o objeto da narração. Essa "construção" muitas vezes se dá, na narrativa televisionada, a partir de intervenções do telespectador por meio da resposta a enquetes virtuais ou comentários emitidos através da internet. Isso aproxima o telespectador, antes "mudo", da narrativa e do evento, a partir da possibilidade de interação, tornando o telespectador participante direto da construção do narrar. O narrador também conversa com o(s) comentarista(s) e/ou com o(s) repórter(es), tornando a narração potencialmente dialógica. Em uma partida de futebol, por exemplo, o narrador consegue manter, pelo menos, três diálogos: 
narrador e telespectador, narrador e comentarista, além de narrador e repórter(es) de campo. A narração de MOBA pode ter esse ar dialógico, consoante Bakhtin/Voloshínov (2014), entre o espectador e o narrador, aproximando-se assim da narração futebolística. Outra similaridade entre as narrações é a presença de comentaristas durante a narrativa. Porém, na narração de MOBA há uma particularidade interessante: o espectador pode acompanhar o jogo a partir de transmissões online ou assistir a partida diretamente do aplicativo do jogo. No Dota2, por exemplo, ao assistir através do aplicativo do jogo, o espectador tem certa liberdade, logo pode optar por deixar a câmera sob controle do narrador, pode manipulá-la ou deixá-la sob a perspectiva de um jogador específico. Essa liberdade é interessante, pois como ocorrem várias jogadas ao mesmo tempo, o espectador tem o livre arbítrio de escolher o que quer ver. A final do The International5, por exemplo, contou com 6 narradores oficiais (que estavam no evento, que ocorreu nos EUA): dois transmitindo em língua inglesa, um em chinês, um em russo, um em português e um em espanhol, além de vários outros canais de narração disponíveis pela internet.

Todavia, como se configura esse gênero textual, levando em consideração o raciocínio bakhtiniano (2003) a respeito do conceito de gênero? Como podemos entender seu conteúdo temático, sua estrutura composicional e seu estilo? Antes de responder a essas perguntas, vamos elucidar como compomos os dados que analisaremos.

\section{Aspectos metodológicos}

O corpus deste trabalho é composto por dois excertos de narrativas de LoL. Foi feita transcrição simples: consideramos os termos utilizados durante a narração. Recorremos a este recurso por se tratar de um gênero especificamente oral.

A transcrição de narrativa número 1 diz respeito a um jogo $1 \times 1$ entre dois jogadores profissionais, que ocorreu no programa Encontro com Fátima Bernardes, da emissora de televisão Rede Globo, que foi ao ar no dia 28 de julho de 2014. O jogo ganhou repercussão nacional no programa após a final do CBLOL de 2014 ocupar o ginásio do Maracanãzinho, no Rio de Janeiro, espaço conhecido por receber diversas competições esportivas importantes. Seria a primeira vez que a final de um campeonato de E-sports lotaria um ginásio em território nacional. Vale ressaltar que todos os oito mil assentos disponíveis para assistir ao evento foram vendidos nas primeiras três horas após a abertura das vendas. Na modalidade $1 \times 1$, os dois jogadores vão pela trilha do meio e se enfrentam até um deles adquirir o firstblood (um jogador derrotar o outro) ou até um deles derrubar a primeira torre. No jogo em questão, os jogadores Daniel "Dans" Dias, da equipe KaBuM! E-sports, e Gabriel "Revolta" Henud, da equipe INTZ e-sports, se enfrentam durante 0 programa de televisão para mostrar como funciona a dinâmica do jogo. Seus computadores foram colocados frente a frente, fazendo com que um jogador não tivesse acesso às imagens da tela do outro. Esta posição não é aleatória, uma vez que as estratégias utilizadas por um jogador não podem ser compartilhadas com seu adversário, caso contrário elas podem se tornar ineficientes. $O$ jogo foi narrado por Diego "Toboco" Pereira, narrador profissional de e-sports. Na ocasião, o narrador não estava acompanhado de um comentarista, como podemos perceber na transcrição que trazemos a seguir, na análise. Vale ressaltar que o narrador também é um jogador em potencial, portanto precisa conhecer os mecanismos do jogo, entender o que cada herói pode fazer e como se configuram suas habilidades, como, por exemplo, quanto de dano cada "magia" evocada por um herói pode causar em seu adversário, precisa conhecer a geografia do mapa, reconhecer todos os itens, entre outros conhecimentos que são próprios do jogador de MOBA.

A transcrição de narrativa número 2 foi feita a partir de um excerto de uma partida entre as equipes Pain Gaming e-sports e KaBuM! E-sports, de fevereiro de 2015, durante o Circuito Brasileiro de LoL, o CBLOL. O excerto diz a respeito a uma parte da partida, na qual alguns jogadores da equipe KaBuM! tentam avançar sobre a torre da equipe 
PainGaming, e um jogador, Gabriel "Kami" Santos, faz uma grande jogada defensiva, que possibilitou 0 ataque do jogador Felipe "brTT" Gonçalves, da PainGaming, a de dois jogadores da KaBuM!: Márcio "Eryon" Reis e Rodrigo "Digolera" Haddad. A narração foi feita por Toboco, que dessa vez estava acompanhado pelo comentarista de e-sports Guilherme "Tixinha" Cheida. O evento CBLOL foi promovido com algumas fases via internet e teve sua etapa final realizada no estádio de futebol Palestra Allianz, o estádio de futebol do time do Palmeiras, na cidade de São Paulo. O evento teve, além de milhares de espectadores via internet, 12 mil pessoas que lotaram o estádio de futebol para ver de perto a final do campeonato.

\section{Análise do corpus: investigando a narração de MOBA}

Iniciaremos a análise a partir da leitura da transcrição número um. Após análise de alguns aspectos, partiremos para a transcrição número dois. Ao final das análises, construímos um quadro com as principais características do gênero narrativa e suas principais diferenças em relação à narrativa do futebol.

\section{Transcrição \#1: LOL no programa Encontro} com Fátima Bernardes 5

Diego Toboco: Bom, aqui eles vão fazer um confronto x1 né, 1 contra 1.

Fátima Bernardes: eles estão jogando entre eles? É isso?

Diego Toboco: Exatamente. Um está usando o campeão Nocturne, como a gente chama e ele está usando a Vi que apareceu na reportagem como cosplay, ele foi para cima agora, usa o portador do anoitecer, já tem uma troca contra o Dans, Dans tem que recuar, usa o flash agora o Revolta, continua indo para cima, pode ter o dive, vai acabar sendo morto e tá ali, firstblood, garantiu a eliminação o Revolta.

O conteúdo temático deste gênero pode ser entendido como uma narrativa prototípica de uma partida de LOL, com enunciados descritivos

\footnotetext{
${ }^{5}$ Disponivel em https://www.youtube.com/watch?v=3tgEII23cTI. Acesso em 15/09/2015, às 19:29.

6 Abreviação de Costume Play. Pode-se traduzir por representação de personagem a caráter, disfarce ou fantasia.
}

construídos por um narrador observador. Vale ressaltar que, como qualquer narrativa esportiva, há determinada modulação na entonação quando a atividade chega próximo ao clímax, que, no exemplo anterior, seria o firstblood (a vitória sobre o adversário). A configuração do que se é narrado e os recursos que envolvem 0 trabalho do narrador contribuem para a variedade do conteúdo temático. Se, por exemplo, for uma narração via rádio, o narrador precisa construir imagens a partir das narrativas, precisa descrever, além das jogadas, o espaço físico e os jogadores, o clima, etc. No entendo, podemos assumir que há certa estabilidade no conteúdo temático de narrativas esportivas.

Bakhtin (2003, p. 266) salienta que a estrutura composicional se refere aos "[...] tipos de construção do conjunto, de tipos de acabamento". Em outras palavras, os elementos da estrutura composicional são aqueles que nos permitem reconhecer um gênero como tal, é o que nos faz distinguir uma narrativa fantástica de uma receita de bolo, por exemplo. Sobre esse pilar, podemos dizer que nosso gênero se revela enquanto narrativa esportiva, pois se aproxima da lógica dos gêneros narrativas em geral. $O$ narrador comenta e narra aquilo que vê. Inclusive descreve a jogada, cria exemplos e conexões com outros fatos para facilitar o entendimento de seu interlocutor.

Como podemos observar, alguns elementos na transcrição acima se aproximam de uma narrativa esportiva de futebol, como, por exemplo, a progressão das atividades dos jogadores e o anúncio do objetivo que finaliza a seção da narrativa (o que seria o gol do futebol). Porém há, no que diz respeito ao pilar "estilo", assumido por Bakhtin (2003), vários estrangeirismos. Por exemplo: no trecho "[...] pode ter o dive [...]", entendemos que dive aqui significa avanço, o que não foge à tradução literal, pois, to dive significa mergulhar, em inglês. Uma questão interessante a se pensar é que, mesmo com o jogo totalmente traduzido para o português, algumas jogadas/ações seguem recebendo nomenclaturas inglesas, ou, na maioria dos casos, palavras derivadas de estrangeirismos: to dive (inglês) - dive (como no exemplo acima) - divar (executar o dive). 
Esse deve ser um ponto a ser investigado com mais detalhes posteriormente em outros trabalhos: as especificidades dos termos em jogos online/e-sports. Essa categoria se afasta em certa medida da narrativa de futebol que, por mais que se tenha vocabulário específico, há pouca alusão a estrangeirismos na narração do futebol, no momento em que se narra o jogo.

Há, também, certa diferença no público alvo das narrativas. Ao passo que a narrativa de futebol se direciona para um público mais adulto, a narração de $M O B A$ se dirige a espectadores mais jovens e mais especializados, o que resulta em uma narrativa com termos linguísticos menos coloquiais e mais específicos.

Entretanto, nessa modalidade de jogo, o jogo 1 $x$, o foco do narrador é único: a trilha do meio. É nela e somente nela que os jogadores podem se enfrentar, delimitando o olhar do narrador e, consequentemente, o olhar do espectador. Nesse caso, a narração de MOBA se assemelha à de futebol. Há apenas um único ponto de foco, um único lugar para se observar.

Seguiremos para a transcrição de narrativa de MOBA número 2, trecho retirado de um jogo feito na modalidade $5 \times 5$, a modalidade canônica de jogos MOBA.

\section{Transcrição \#2: Kami no $\mathrm{CBLOL}^{7}$}

Toboco: $O$ dragão ainda não tá vivo, eles podem aproveitar agora, quatro jogadores para levar a primeira torre do jogo, Tixinha. O brTT vai tentar defender, será que ele fica por ali, eles sabem o potencial de dive...Valquíria para longe.

Tixinha: É... vão acabar os minion... o Kami tá chegando, vai dar ruim! Nossa!

Toboco: Olha só o que o Kami fez, jogou quatro jogadores para trás, pode rolar a eliminiação, Eryon sendo focado e eliminado pelo brTT, chega também o Túlio, o Digolera é o foco, vai tentando catar, recebe muito dano...Double kill pro brTT... Que jogada mitológica do Kami, Tixinha.

O conteúdo temático, assim como na transcrição numero um é a partida de LOL. Neste exemplo, uma partida em sua configuração canônica: cinco jogadores de uma equipe contra cinco

7 Disponível em https://www.youtube.com/watch?v=Qx0uMRXDd0. Acesso em 16/09/2015, às 23:18. jogadores de outra equipe. Como dito anteriormente, o objetivo nesta modalidade é vencer a equipe ao derrotar todos os membros e avançar em alguma trilha até a team base adversária, quebrando todas as estruturas.

Sobre o pilar composicional, também é uma narrativa, pois, existe a figura do narrador e, nesse caso, do comentarista. Podemos reforçar a ideia de Bakhtin/Voloshinov (2014) sobre o dialogismo, ao olharmos para a relação entre narrador, comentarista e telespectador. O texto vai se construindo a partir do diálogo entre os interlocutores. O narrador constrói as imagens expondo a geografia do mapa (a primeira torre do jogo) e começa a descrever as ações dos jogadores, dialoga com o comentarista, que tem seu comentário inibido após a chegada de outro jogador. Há também a presença dos elementos específicos do gênero em questão, como as palavras de origem estrangeira, tal qual o exemplo anterior.

O diálogo é um elemento basal na narrativa, pois, mesmo sem a participação de um comentarista, o narrador conversa com o espectador. Mesmo que não frente a frente, o fluxo dialógico acontece logo que a narrativa completa a imagem, seja ela construída através da própria narrativa ou contemplada através da tela do computador ou da televisão.

Para entender esse aspecto dialógico da narração, e como esse aspecto está presente tanto em narrativas de futebol como em de e-sports, o excerto abaixo é do texto de uma narrativa de futebol e foi retirado de SANTOS, 2012. Na oportunidade, o narrador está apresentando um jogo de futebol entre as equipes São Paulo e Goiás, pelo campeonato brasileiro de futebol. $\mathrm{O}$ jogo foi televisionado pela Rede Globo.

Olha o Júlio César! Chegou antes pra fazer o corte pelo time do São Paulo. No meio o Rodrigo. Ta aí Jorge Wagner. Apertado, na dividida a bola é tocada pra fora. [...] Jorge Wagner na bola. Lá vai o primeiro lance de perigo pra área do Goiás. Partiu Jorge Wagner, bateu, venenosa! Harlei! Um soco na bola o goleiro do Goiás! O próprio Jorge ainda tenta aproveitar, o time do Goiás recupera a posse da bola. Tentou a jogada o Ramalho, fica com o time do São Paulo apertando a saída evitando o contra-ataque arremesso 
lateral para o time do Goiás (SANTOS, 2012. p.40-42).

O diálogo com o telespectador é evidente, desde a escolha do tempo verbal em "Olha o Júlio Cesar![...]" até a cadência das informações para a construção da imagem. Há somente um foco, a bola. Os movimentos construídos ao redor da bola é que são narrados. A escolha dos termos linguísticos e a questão do olhar do narrador diferem da narrativa de MOBA.

$\mathrm{O}$ que garante que, jogadores que assistam a uma partida de MOBA pelo computador, mantenhamse conectados a câmera do narrador? Nosso argumento é o de que o narrador precisa construir em sua narração um percurso interessante que prenda a atenção do seu telespectador, forçando o narrador a ser mais dinâmico. Essa tese é sustentada pelo fato de que, no jogo de MOBA $5 \times 5$, nem sempre todos os jogadores participam da jogada que está sendo narrada, como é o caso da transcrição número dois, em que, naquele momento do jogo, três jogadores de uma equipe enfrentaram quatro jogadores da equipe adversária.

Nesse caso o narrador, enquanto engenheiro do gênero discursivo que narra, precisa mais do que nunca envolver 0 espectador em suas trilhas narrativas para que se tenha uma narração de sucesso, pois, em uma partida de MOBA, o espectador controla o que quer ver.

Hoje em dia, o poder do espectador é permitido em alguma medida em tecnologias pay-perview em campeonatos de futebol: existe um numero $x$ de câmeras que 0 assinante pode escolher. Entretanto, essas câmeras são limitadas e não permitem que o telespectador tenha controle da imagem, ou, controle total do que olhar. O narrador de MOBA precisa, de certa forma, seduzir seu espectador e estabelecer com ele diálogos apropriados para conquistar não somente a atenção de seus ouvidos, mas, também, a de seu olhar.

Podemos, a partir do excerto de Santos (2012) e da transcrição \#2, afirmar que o gênero narrativa esportiva tem certo encadeamento das ações narradas. É necessário que haja certa coesão no narrar, entre um fato e outro. Esse encadeamento muitas vezes não se dá por elementos textuais coesivos, por conectivos. No trecho da narrativa de MOBA "[...] Digolera é o foco, vai tentando catar, recebe muito dano...Double kill pro brTT... Que jogada mitológica do Kami, Tixinha" há uma enumeração de ações, faladas na sequência em que ocorrem na partida. A narração é finalizada com "que jogada mitológica do Kami, Tixinha", o que categoriza o movimento do jogador Kami e estabelece a coesão entre os termos enumerados anteriormente. Nesse caso, podemos sustentar o argumento de que o estilo do gênero analisado permite que a coesão entre os fatos narrados se construa dessa forma. Para o pensamento bakhtiniano (2003), no que diz respeito à questão do estilo, há o estilo individual, construído a partir da singularidade do sujeito enunciador, e o estilo do gênero, que é frequente em um dado contexto enunciativo. Em narrativas de MOBA, o estilo individual costuma ser bastante presente.

Construímos o quadro 2 , a seguir, que contempla diferenças e semelhanças entre a narrativa de MOBA e a narrativa de futebol, de acordo com nossa análise:

Quadro 2: Comparativo entre elementos da narração de futebol e da narração de MOBA.

\begin{tabular}{|c|c|}
\hline $\begin{array}{l}\text { Algumas características do } \\
\text { gênero Narração de Futebol }\end{array}$ & $\begin{array}{l}\text { Algumas características do } \\
\text { gênero Narração de MOBA }\end{array}$ \\
\hline $\begin{array}{l}\text { Admite Narradores e } \\
\text { Comentaristas }\end{array}$ & $\begin{array}{l}\text { Admite Narradores e } \\
\text { Comentaristas }\end{array}$ \\
\hline $\begin{array}{l}\text { Narrativa focalizada: o foco é a } \\
\text { bola e toda a narração se } \\
\text { constrói ao redor dela }\end{array}$ & $\begin{array}{l}\text { Narrativa multifocal: existem } \\
\text { vários pontos de foco }\end{array}$ \\
\hline $\begin{array}{l}\text { Espectador [parcialmente] } \\
\text { passivo }\end{array}$ & Espectador [potencialmente] ativo \\
\hline $\begin{array}{l}\text { Linguagem e escolhas lexicais } \\
\text { simples }\end{array}$ & $\begin{array}{l}\text { Linguagem e escolhas lexicais } \\
\text { complexas }\end{array}$ \\
\hline Admite termos específicos & Admite termos específicos \\
\hline Gênero prioritariamente oral & Gênero prioritariamente oral \\
\hline $\begin{array}{l}\text { Admite uso de vernáculos } \\
\text { locais }\end{array}$ & $\begin{array}{l}\text { Admite uso de estrangeirismos e } \\
\text { vernáculos estrangeiros }\end{array}$ \\
\hline $\begin{array}{l}\text { Narrativa encadeada } \\
\text { encadeamento de ações }\end{array}$ & $\begin{array}{l}\text { Narrativa encadeada } \\
\text { encadeamento de ações }\end{array}$ \\
\hline
\end{tabular}

Fonte: Elaborado pelos pesquisadores 


\section{Conclusão}

Nosso propósito, neste artigo, foi investigar o gênero discursivo Narrativa esportiva de MOBA. Para tanto, estabelecemos alguns parâmetros de comparação entre a narrativa de MOBA e a narrativa de futebol. Ao propor esta investigação, nossa expectativa foi a de contribuir com os estudos que ora têm sido feitos a respeito de gêneros discursivos, ao pôr em evidência acadêmica a narrativa esportiva de e-sports, prática que tem se tornado muitíssimo comum recentemente.

A partir da leitura e análise dos trechos de narrativas de MOBA discutidos em nossa análise, podemos pensar em certas proximidades e diferenças entre a narração de MOBA e a narrativa de futebol, conforme o quadro apresentado ao final da análise. Nas transcrições de MOBA, como vimos, mesmo com a ausência de um comentarista, o narrador dialoga com a apresentadora de TV e com os telespectadores. Na transcrição de futebol exposta, narrador e comentaristas exercem sua função canônica: o primeiro narra os acontecimentos do certame e o segundo imprime certa opinião sobre a narração.

O conteúdo temático dos dois exemplos de narrativas de MOBA que apresentamos é a própria partida do jogo. Sobre a questão composicional, podemos dizer, a princípio $^{8}$, que ela se monta prioritariamente na narrativa. A respeito do estilo do gênero podemos levantar alguns elementos importantes: o caráter caótico da narrativa (várias coisas acontecem ao mesmo tempo); o caráter interativo/dialógico do processo de narração (narrador/comentarista, narrador/espectador); os termos próprios do gênero (estrangeirismos, palavras derivadas de palavras inglesas); o olhar multifocal do narrador/espectador (o narrador/espectador pode escolher o que quer mostrar/ver).

Outro ponto interessante que pudemos observar a partir da análise é a diferença entre a

\footnotetext{
${ }^{8}$ Vale ressaltar que definimos a priori pois precisaríamos de outro trabalho para detalhar a estrutura composicional deste gênero.
}

narrativa de MOBA e outras narrativas esportivas no que diz respeito ao olhar do narrador e aquilo que é apresentado ao telespectador. No futebol, a narração se dá a partir de um único ponto de foco (a bola). Toda a narrativa é construída ao redor daquele ponto. No caso do MOBA, a narração é multifocal, pois acontecem vários eventos ao mesmo tempo, exigindo, do narrador de $M O B A$, certa perspicácia na construção da narrativa e na seleção de seu foco, para conseguir estabelecer diálogos com seu públicoalvo. Há diferença também na relação narrador/espectador: no futebol, o espectador é parcialmente passivo enquanto que o do MOBA é potencialmente ativo.

\section{Referências}

BAKHTIN, Mikhail. Estética da criação verbal. São Paulo: Martins Fontes, 2003. $4^{\mathrm{a}} \mathrm{ed}$.

BAKHTIN, Mikhail/VOLOCHÍNOV. Marxismo e filosofia da linguagem: problemas fundamentais do método sociológico da linguagem. São Paulo: Hucitec, 2014. 16. ed.

FIORIN, José Luiz de. Introdução ao pensamento de Bakhtin. São Paulo: Ática, 2006.

HUIZINGA, Johan. Homo Ludens - o jogo como elemento da cultura. São Paulo: Ed. Perspectiva, 1980.

MARCUSCHI, Luiz Antônio. Gêneros textuais: definição e funcionalidade. In: DIONISIO, A. P. et al. Gêneros textuais e ensino. São Paulo: Parábola Editorial, 2010.

Produção textual, análise de gêneros $e$ compreensão. São Paulo: Parábola Editorial, 2008.

PEREIRA, M. H. de M. SILVA, D. J. A. O gênero receita em sala de aula: trabalhando o contexto real de produção de um gênero. In: Revista Intersecções - Edição 12 - Ano 7 - Número 1 maio/2014.

RIBEIRO. Pollyanne Bicalho. Funcionamento do gênero do discurso. BAKHTINIANA, São Paulo, v. 1, n. 3, p. 54-67, 1으. 2010.

SANTOS, C. A. R. A narração esportiva de futebol: análise discursiva de um fenômeno midiático. 2010. 181 f. Dissertação (Mestrado em Linguística e Língua Portuguesa) - Pontifícia Universidade Católica de Minas Gerais, Belo Horizonte, 2010. 
SANTOS, C. A. R. Narração esportiva de futebol e composicionalidade: uma proposta de estudo textual-discursiva das sequências textuais. In: Estudos da Língua(gem). Vitória da Conquista v. 10 , n. 2 p. 31-48 dezembro de 2012.

\section{COMO CITAR ESSE ARTIGO}

DE SOUZA, Danilo Sobral; PEREIRA, Márcia Helena de Melo; VENTURA, Adilson. Narrativa esportiva de MOBA: que gênero é esse?. Signo, Santa Cruz do Sul, v. 44, n. 80, p. 157-169, ago. 2019. ISSN $1982-2014$. doi: https://doi.org/10.17058/signo.v44i80.13252. 